\title{
ANALISA KEPUASAN PASIEN DALAM PELAYANAN KESEHATAN DI PUSKESMAS PEMBANTU PARARAPAK KABUPATEN BARITO SELATAN TAHUN 2019
}

\author{
Ivana, Theresia ${ }^{1}$, Taraneti, Desi ${ }^{2}$, Permana, Luckyta Ibna ${ }^{3}$ \\ ${ }^{1,2,3}$ Sekolah Tinggi Ilmu Kesehatan Suaka Insan Banjarmasin, 70119, Indonesia
}

Email: theresiaivana84@gmail.com

\begin{abstract}
ABSTRAK
Latar belakang Puskesmas merupakan fasilitas kesehatan yang menyelenggarakan upaya kesehatan masyarakat dan perseorangan tingkat pertama, dengan mengutamakan upaya promotif dan preventif. Puskesmas merupakan salah satu fasilitas kesehatan yang banyak dimanfaatkan oleh masyarakat. Setiap pelayanan jasa akan berdampak pada kemauan dari pelanggan untuk mendatangi tempat pelayanan dilaksanakan. Kepuasan pelanggan mempengaruhi kunjungan tersebut, sehingga pelayanan kesehatan yang prima menjadi hal yang utama dalam pelayanan kesehatan. Kepuasan pasien berhubungan langsung dengan pelayanan yang diberikan di puskesmas, apabila pemberi layanan melakukan service excellent diharapkan tingkat kepuasan pasien akan meningkat.

Metode Penelitian deskriptif kuantitatif yang bertujuan melakukan analisa kepuasan pasien dalam pelayanan kesehatan di Puskesmas Pembantu Pararapak Kabupaten Barito Selatan tahun 2019. Populasi penelitian 70 orang, jumlah sampel yang didapatkan 45 orang responden yang ditentukan dengan teknik purposive sampling. Variabel tunggal penelitian yaitu kepuasan pasien. Pengambilan data menggunakan kuesioner Service Quality terdiri atas lima dimensi kepuasan

Hasil Kepuasan pasien dalam pelayanan kesehatan di Puskesmas Pembantu Pararapak pada dimensi tangible $71,1 \%$ sangat memuaskan, pada dimensi reliability 55,6\% puas, dimensi responsiveness $71,1 \%$ sangat puas, dimensi assurance $60 \%$ sangat puas, dan dimensi empathy $44,4 \%$ puas.

Kesimpulan Secara umum kepuasan pasien dalam pelayanan kesehatan di Puskesmas Pembantu Pararapak menunjukkan sangat puas terhadap pelayanan kesehatan yang diperikan di Puskesmas Pembantu Pararapak, Kabupaten Barito Selatan, tahun 2019
\end{abstract}

Kata kunci Kesehatan, Kepuasan, Pasien, Pelayanan, SERVQUAL 


\section{PENDAHULUAN}

Kepuasan adalah suatu tingkat perasaan pasien yang timbul sebagai akibat dari kinerja layanan kesehatan yang diperoleh setelah pasien membandingkan dengan apa yang diharapkan. Apabila hasil yang diperoleh melebihi dari yang dibayangkan dan diharapkan, maka akan tercipta perasaan puas. Kepuasan merupakan perihal (yang bersifat puas), kesenangan dan kelegaan (KBBI, 2020). Setiap pelayana jasa akan berdampak pada kemauan dari pelanggan untuk mendatangi tempat dimana pelayanan dilaksanakan. Apabila pelanggan merasa puas dari pelayanan yang diterima, maka mereka akan kembali untuk membeli produk yang ditawarkan (Tando, 2013).

Puskesmas adalah fasilitas pelayanan kesehatan yang menyelenggarakan upaya kesehatan masyarakat dan upaya kesehatan perseorangan tingkat pertama, dengan mengutamakan upaya promotif dan preventif untuk mencapat derajat kesehatan masyarakat yang setinggitingginya di wilayah kerjanya (Permenkes, 2014). Puskesmas merupakan salah satu fasilitas kesehatan yang banyak dimanfaatkan oleh masyarakat dimana puskesmas dan jejaringnya menjadi ujung ombak dari pelayanan kesehatan di Indonesia.

Fungsi puskesmas ialah sebagai penyelenggara pelayanan kesehatan dasar, baik perseorangan maupun pelayanan kesehatan kepada masyarakat secara umum. Pelayanan kesehatan perseorangan diantaranya yaitu pelayanan rawat jalan dan rawat inap (bagi puskesmas tertentu). Sementara pelayanan kesehatan masyarakat yaitu upaya promotif dan preventif seperti penyuluhan kesehatan, pelaksana program kesehatan bagi ibu dan anak serta program kesehatan lanjut usia, dan kelompok masyarakat dengan penyakit tertentu.
Dapat dikatakan bahwa tingkat kepuasan pelanggan terhadap kualitas pelayanan merupakan faktor yang penting dalam mengembangakan suatu sistem penyediaan pelayanan yang tanggap terhadap kebutuhan pelanggan, meminimalkan biaya dan waktu serta memaksimalkan dampak positif pelayanan terhadap populasi sasaran. Puskesmas wajib memberikan pelayanan kesehatan yang memuaskan pelanggan atau dalam hal ini pasien yang berkunjung dalam usahanya menyehatkan bangsa dan peningkatan kualitas pelayanan (Astuti, 2019).

Beberapa metode tentang kepuasan pelanggan antara lain yaitu, metode Importance Performance Analysis (IPA), metode Servqual dan metode Customer Satisfaction Index (CSI). Metode Servqual sendiri merupakan suatu metode yang didasarkan atas lima dimensi kualitas yang digunakan sebagai pengukur kualitas pelayanan yang diberikan perusahaan (Parasuraman, 1998). Kelima dimensi tersebut yaitu: tangibles, reliability, responsiveness, assurance dan empathy.

Puskesmas pembantu Pararapak merupakan puskesmas jejaring yang berada di wilayah binaan Puskesmas Kalahien, Kabupaten Barito Selatan. Data kunjungan pasien di Puskesmas Pembantu Pararapak pada tahun 2017 yaitu sebanyak 727 kunjungan, dengan rata-rata pasien sebanyak dua orang setiap harinya. Pada tahun 2018 terjadi peningkatan angka kunjungan yaitu sebanyak 2.131 kunjungan atau sama dengan enam orang pasien setiap harinya.

Hasil studi pendahuluan yang telah dilakukan pada minggu pertama bulan Mei 2020 didapatkan hasil perhitungan pada kotak kepuasan atas pelayanan kesehatan yang terdiri dari tiga kategori, yaitu sangat puas, cukup puas dan tidak puas. Dari 10 orang yang berpartisipasi diperoleh data 
dua orang (20\%) sangat puas, tujuh orang (70\%) cukup puas dan satu orang $(10 \%)$ tidak puas. Secara kualitatif pasien dalam kategori sangat puas dan cukup puas menyatakan pelayanan kesehatan yang diterima cukup baik diantaranya petugas kesehatan cukup aktif dalam memeriksa dan melayani, penjelasan tentang penyakit dan pengobatan dapat dipahami dengan jelas. Sedangkan dalam kategori tidak puas, pasien menyatakan ruang tunggu di puskesmas pembantu kurang besar dan kursi terbatas sehingga pasien tidak mendapatkan tempat duduk. Selain itu pasien mengusulkan agar puskesmas dibuka 24 jam, agar maksimal dalam memberikan pelayanan kesehatan.

Tingkat kepuasan pasien berhubungan langsung dengan pelayanan yang diberikan di fasilitas kesehatan. Apabila selaku pemberi layanan kesehatan telah dilaksanakan secara maksimal, diharapkan tingkat kepuasan pasien akan tinggi. Oleh sebab itu penulis tertarik meneliti kepuasan pasien dalam pelayanan kesehatan di Puskesmas Pembantu Pararapak tahun 2019.

\section{METODE}

Penelitian deskriptif kuantitatif yang bertujuan melakukan analisa kepuasan pasien dalam pelayanan kesehatan di Puskesmas Pembantu Pararapak Kabupaten Barito Selatan tahun 2019. Populasi penelitian 70 orang, jumlah sampel yang didapatkan 45 orang responden yang ditentukan dengan teknik purposive sampling. Variabel tunggal penelitian yaitu kepuasan pasien. Pengambilan data menggunakan kuesioner Service Quality terdiri atas lima dimensi kepuasan dan telah dilakukan uji validitas dan reliabilitas dengan hasil layak untuk digunakan sebagai kuesioner mengukur kepuasan pasien rawat jalan yang berkunjung/ berobat ke puskesmas
(Utama, 2017). Analisa data univariat menggunakan tabel distribusi frekuensi untuk menyajikan data hasil penelitian..

\section{HASIL}

\section{a. Karakteristik responden penelitian}

Tabel 1. Distribusi frekuensi responden berdasarkan umur, jenis kelamin, pekerjaan, dan pendidikan terakhir

\begin{tabular}{|c|c|c|c|}
\hline \multicolumn{2}{|c|}{ Karakteristik } & \multirow{2}{*}{$\begin{array}{c}\begin{array}{c}\text { Frekuensi } \\
(\mathrm{n}=45)\end{array} \\
7\end{array}$} & \multirow{2}{*}{$\begin{array}{c}\text { Persentase } \\
(\%)\end{array}$} \\
\hline Umur & $17-25$ tahun & & \\
\hline & 26-35 tahun & 10 & 22,2 \\
\hline & 36-45 tahun & 13 & 28,9 \\
\hline & $46-55$ tahun & 13 & 28,9 \\
\hline & 56-65 tahun & 2 & 4,4 \\
\hline Jenis & Laki-laki & 9 & 20 \\
\hline Kelamin & Perempuan & 36 & 80 \\
\hline \multirow[t]{5}{*}{ Pekerjaan } & $\begin{array}{l}\text { Tidak bekerja/ } \\
\text { IRT }\end{array}$ & 19 & 42,2 \\
\hline & Wiraswasta & 3 & 6,67 \\
\hline & Petani & 18 & 40 \\
\hline & PNS & 1 & 2,2 \\
\hline & Lainnya & 4 & 8,93 \\
\hline Pendidikan & $\mathrm{SD} /$ sederajat & 5 & 11,1 \\
\hline \multirow[t]{3}{*}{ Terakhir } & SLTP/ sederajat & 22 & 48,9 \\
\hline & SLTA/ sederajat & 15 & 33,3 \\
\hline & $\begin{array}{c}\text { Perguruan } \\
\text { Tinggi }\end{array}$ & 3 & 6,67 \\
\hline
\end{tabular}

Karakteristik 45 orang responden diketahui bahwa menurut kategori usia, paling banyak responden dalam rentang usia dewasa akhir (36-35 tahun) sebanyak $28,9 \%$ dan rentang usia pertengahan atau lansia awal (46-55 tahun) sebanyak 28,9\%. Selain itu, responden paling banyak berjenis kelamin perempuan sebanyak $80 \%$. Berdasarkan pekerjaan, mayoritas responden tidak bekerja/ IRT sebanyak 42,2\% dan memiliki pendidikan terakhir paling banyak tingkat SLTP/sederajat sebanyak $48,9 \%$. 
dalam kenyataan berada dalam kategori puas sebanyak $55,6 \%$.

\section{b. Hasil penelitian berdasarkan lima dimensi Servqual}

Tabel 2. Distribusi frekuensi responden berdasarkan dimensi bukti fisik (tangible)

\begin{tabular}{ccccc}
\hline \multirow{2}{*}{ Kategori } & \multicolumn{2}{c}{ Harapan } & \multicolumn{2}{c}{ Kenyataan } \\
\cline { 2 - 5 } & $\begin{array}{c}\text { Frekuensi } \\
(\mathrm{n}=45)\end{array}$ & $\begin{array}{c}\text { Persentase } \\
(\%)\end{array}$ & $\begin{array}{c}\text { Frekuensi } \\
(\mathrm{n}=45)\end{array}$ & $\begin{array}{c}\text { Persentase } \\
(\%)\end{array}$ \\
\hline Sangat & 34 & 75,6 & 32 & 71,1 \\
Puas & & & & \\
Puas & 11 & 24,4 & 12 & 26,7 \\
Kurang & 0 & 0 & 1 & 2,2 \\
Puas & & & & 0 \\
Tidak & 0 & 0 & 0 & 0 \\
Puas & & & & \\
\hline
\end{tabular}

Tabel 2 menunjukkan bahwa kepuasan pasien dalam pelayanan kesehatan di Puskesmas Pembantu Pararapak berdasarkan dimensi bukti fisik (tangible) harapan berada dalam kategori sangat puas yaitu $75,6 \%$ sementara dalam kenyataan berada dalam kategori sangat puas sebesar $71,1 \%$.

Tabel 3. Distribusi frekuensi responden berdasarkan dimensi kehandalan (reliability)

\begin{tabular}{ccccc}
\hline \multirow{2}{*}{ Kategori } & \multicolumn{2}{c}{ Harapan } & \multicolumn{2}{c}{ Kenyataan } \\
\cline { 2 - 5 } & $\begin{array}{c}\text { Frekuensi } \\
(\mathrm{n}=45)\end{array}$ & $\begin{array}{c}\text { Persentase } \\
(\%)\end{array}$ & $\begin{array}{c}\text { Frekuensi } \\
(\mathrm{n}=45)\end{array}$ & $\begin{array}{c}\text { Persentase } \\
(\%)\end{array}$ \\
\hline Sangat & 24 & 53,3 & 20 & 44,4 \\
Puas & & & & 55,6 \\
Puas & 21 & 46,7 & 25 & 0 \\
Kurang & 0 & 0 & 0 & 0 \\
Puas & & & & \\
Tidak & 0 & 0 & 0 & \\
Puas & & & &
\end{tabular}

Tabel 3 menunjukkan bahwa kepuasan pasien dalam pelayanan kesehatan di Puskesmas Pembantu Pararapak berdasarkan dimensi kehandalan (reliability) harapan berada dalam kategori sangat puas sebesar 53,3\% sementara
Tabel 4. Distribusi frekuensi responden berdasarkan dimensi ketanggapan (responsiveness)

\begin{tabular}{ccccc}
\hline \multirow{2}{*}{ Kategori } & \multicolumn{2}{c}{ Harapan } & \multicolumn{2}{c}{ Kenyataan } \\
\cline { 2 - 5 } & $\begin{array}{c}\text { Frekuensi } \\
(\mathrm{n}=45)\end{array}$ & $\begin{array}{c}\text { Persentase } \\
(\%)\end{array}$ & $\begin{array}{c}\text { Frekuensi } \\
(\mathrm{n}=45)\end{array}$ & $\begin{array}{c}\text { Persentase } \\
(\%)\end{array}$ \\
\hline Sangat & 32 & 71,1 & 32 & 71,1 \\
Puas & & & & \\
Puas & 13 & 28,9 & 13 & 28,9 \\
Kurang & 0 & 0 & 0 & 0 \\
Puas & & & & 0 \\
Tidak & 0 & 0 & 0 & 0 \\
Puas & & & & \\
\hline
\end{tabular}

Tabel 4 menunjukkan bahwa kepuasan pasien dalam pelayanan kesehatan di Puskesmas Pembantu Pararapak berdasarkan dimensi ketanggapan (responsiveness) baik dalam harapan maupun kenyataan berada dalam kategori sangat puas yaitu $71,1 \%$.

Tabel 5. Distribusi frekuensi responden berdasarkan dimensi jaminan (assurance)

\begin{tabular}{ccccc}
\hline \multirow{2}{*}{ Kategori } & \multicolumn{2}{c}{ Harapan } & \multicolumn{2}{c}{ Kenyataan } \\
\cline { 2 - 5 } & $\begin{array}{c}\text { Frekuensi } \\
(\mathrm{n}=45)\end{array}$ & $\begin{array}{c}\text { Persentase } \\
(\%)\end{array}$ & $\begin{array}{c}\text { Frekuensi } \\
(\mathrm{n}=45)\end{array}$ & $\begin{array}{c}\text { Persentase } \\
(\%)\end{array}$ \\
\hline $\begin{array}{c}\text { Sangat } \\
\text { Puas }\end{array}$ & 29 & 64,4 & 27 & 60 \\
Puas & 16 & 35,6 & 18 & 40 \\
Kurang & 0 & 0 & 0 & 0 \\
Puas & & & & 0 \\
Tidak & 0 & 0 & 0 & 0 \\
Puas & & & &
\end{tabular}

Tabel 5 menunjukkan bahwa kepuasan pasien dalam pelayanan kesehatan di Puskesmas Pembantu Pararapak berdasarkan dimensi jaminan (assurance) harapan berada dalam kategori sangat puas sebesar $64,4 \%$ sedangkan dalam kenyataan berada dalam kategori sangat puas sebesar $60 \%$. 
Tabel 6. Distribusi frekuensi responden berdasarkan dimensi empati (empathy)

\begin{tabular}{ccccc}
\hline \multirow{2}{*}{ Kategori } & \multicolumn{2}{c}{ Harapan } & \multicolumn{2}{c}{ Kenyataan } \\
\cline { 2 - 5 } & $\begin{array}{c}\text { Frekuensi } \\
(\mathrm{n}=45)\end{array}$ & $\begin{array}{c}\text { Persentase } \\
(\%)\end{array}$ & $\begin{array}{c}\text { Frekuensi } \\
(\mathrm{n}=45)\end{array}$ & $\begin{array}{c}\text { Persentase } \\
(\%)\end{array}$ \\
\hline $\begin{array}{c}\text { Sangat } \\
\text { Puas }\end{array}$ & 14 & 31,1 & 17 & 37,8 \\
Puas & 26 & 57,8 & 20 & 44,4 \\
Kurang & 0 & 0 & 8 & 17,8 \\
Puas & & & 0 & 0 \\
Tidak & 0 & 0 & 0 & \\
Puas & & & &
\end{tabular}

Tabel 6 menunjukkan bahwa kepuasan pasien dalam pelayanan kesehatan di Puskesmas Pembantu Pararapak berdasarkan dimensi empati (empathy) harapan berada dalam kategori puas sebesar $57,8 \%$, sedangkan dalam kenyataan berada dalam kategori puas sebesar $44,4 \%$.

\section{c. Hasil penelitian kepuasan pasien secara keseluruhan menurut metode Servqual}

Grafik 1. Distribusi frekuensi kepuasan pasien dalam pelayanan kesehatan di Puskesmas Pembantu Pararapak secara keseluruhan dimensi

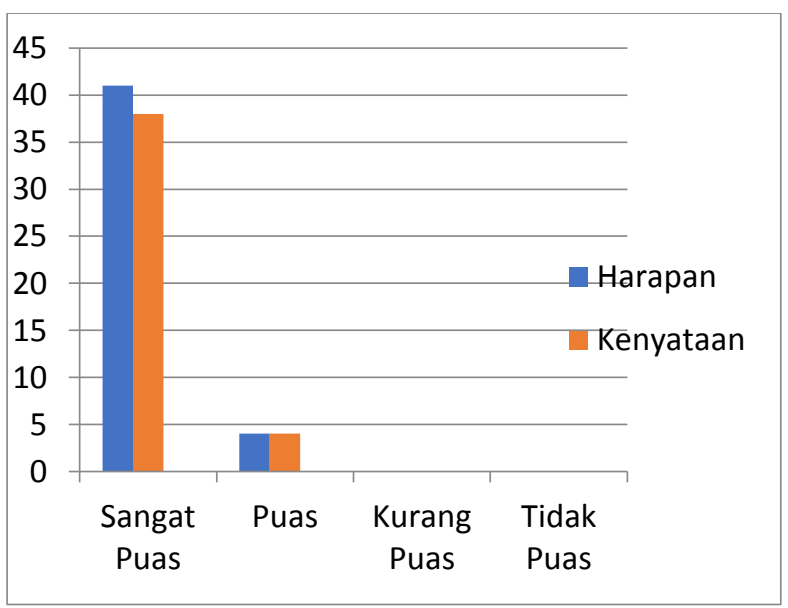

Grafik 1 menggambarkan bahwa kepuasan pasien dalam pelayanan kesehatan di Puskesmas Pembantu Pararapak secara keseluruhan dimensi, berdasarkan harapan berada dalam kategori sangat puas sebanyak 41 responden $(91,11 \%)$ sedangkan dalam kenyataan berada dalam kategori sangat puas sebanyak 38 responden $(84,4 \%)$.

\section{PEMBAHASAN}

Kepuasan adalah respon atau tanggapan konsumen mengenai pemenuhan kebutuhan. Kepuasan merupakan penilaian mengenai ciri atau keistimewaan produk atau jasa, atau produk itu sendiri, yang menyediakan tingkat kesenangan konsumen berkaitan dengan pemenuhan kebutuhan konsumsi konsumen (Zeithaml dan Bitner, 2000). Kepuasan dapat diartikan perasaaan puas dan senang dari individu karena harapan dan kenyataan terpenuhi dengan baik.

Pasien adalah orang yang karena kelemahan fisik atau mentalnya menyerahkan pengawasan dan perawatannya, menerima dan mengikuti pengobatan yang ditetapkan oleh tenaga kesehatan (Hadi, 2013). Kesembuhan pasien dari sakit atau luka berkaitan dengan kepuasan. Hal ini lebih berkaitan dengan konsekuensi sifat pelayanan kesehatan itu sendiri, serta berkaitan pula dengan sasaran dan hasil pelayanan. Kepuasan pasien dalam menilai mutu atau pelayanan yang baik merupakan pengukuran penting yang mendasar bagi mutu pelayanan. Hal ini disebabkan oleh pemberian informasi terhadap suksesnya pemberi layanan bermutu dengan nilai dan harapan pasien yang mempunyai wewenang sendiri untuk menetapkan standar mutu pelayanan yang dikehendaki (Hafizurrachman, 2004).

Zeithaml dan Parasuraman yang dikutip Satrianegara (2014) menyatakan dimensi dari kualitas pelayanan kesehatan yang yang telah banyak digunakan untuk mengukur mutu pelayanan kesehatan 
dikenal sebagai model SERVQUAL (service quality). Servqual menyebutkan lima dimensi mutu pelayanan.

Tabel 2 menunjukkan bahwa kepuasan pasien dalam pelayanan kesehatan di Puskesmas Pembantu Pararapak berdasarkan dimensi bukti fisik (tangible) harapan berada dalam kategori sangat puas yaitu $75,6 \%$ sementara dalam kenyataan berada dalam kategori sangat puas sebesar $71,1 \%$. Responden menyatakan kepuasan terutama dalam item dimana Puskesmas Pembantu Pararapak memiliki persediaan obat yang dibutuhkan pasien, sehingga pasien dapat memperoleh pengobatan sesuai dengan yang dibutuhkan dan tidak memerlukan waktu yang lama. Pada dasarnya kepuasan pasien dapat dipengaruhi oleh beberapa faktor, diantaranya dikemukakan oleh Cut Nur Asma Rani (2013) yaitu ketersediaan obatobatan yang cukup akan mempengaruhi kepuasan pasien. Apabila pasien berkunjung dan memperoleh pengobatan yang sesuai, sehingga pasien tidak perlu berulang-ulang datang ke fasilitas kesehatan maka kepuasan pasien akan meningkat terhadap pelayanan kesehatan yang didapatkan.

Penelitian yang dilakukan oleh Purba (2014) di Puskesmas Huta Rakyat Kecamatan Sidikalang Kabupaten Dairi, kepuasan pasien dalam pelayanan kesehatan dimensi bukti fisik (tangible) berada dalam kategori puas sebesar $75 \%$. Penelitian lain yang dilakukan oleh Candrawati (2015) di Puskesmas ISO dan Non ISO di Kota Denpasar, didapatkan hasil kepuasan pasien dalam pelayanan kesehatan dimensi bukti fisik (tangible) $52 \%$ berada dalam kategori puas sebesar 97,32\% dan 83,89\%. Dapat disimpulkan bahwa item kepuasan pasien dimensi bukti fisik (tangible) adalah sangat memuaskan.

Hasil penelitian pada tabel 3 menunjukkan bahwa kepuasan pasien dalam pelayanan kesehatan di Puskesmas Pembantu Pararapak berdasarkan dimensi kehandalan (reliability) harapan berada dalam kategori sangat puas sebesar 53,3\% sementara dalam kenyataan berada dalam kategori puas sebanyak 55,6\%. Pada dimensi ini responden menyatakan kepuasan terutama dalam item dimana pelayanan Puskesmas Pembantu Pararapak dilakukan dengan cepat, tepat dan cermat. Hal ini sesuai dengan pendapat dari Nurba (2012) bahwa seberapa cepat suatu produk atau jasa dapat diperoleh merupakan hal yang sangat penting.

Pelayanan tepat waktu merupakan salah satu faktor penting yang perlu dipertimbangkan dalam peningkatan kualitas pelayanan. Hal ini sejalan dengan pendapat Cahyono (2008) bahwa pelayanan yang sangat lama, bertele-tele dapat memberi efek ketidakpuasan bagi pasien. Sehingga penting memperhatikan efektifitas waktu dalam memberi pelayanan saat melayani pasien. Peneliti juga memiliki pendapat yang sama, bahwa penting untuk memberikan pelayanan yang tidak hanya cepat, namun juga tepat dan cermat. Mengingat pelayanan kesehatan juga perlu menvalidasi setiap keluhan untuk dapat memberikan pelayanan yang tepat sesuai keperluan pasien.

kepuasan pasien pada tabel 4 menunjukkan bahwa kepuasan pasien dalam pelayanan kesehatan di Puskesmas Pembantu Pararapak berdasarkan dimensi ketanggapan (responsiveness) baik dalam harapan maupun kenyataan berada dalam kategori sangat puas yaitu $71,1 \%$. Responden memberikan respon sangat puas pada item dimana petugas Puskesmas Pembantu Pararapak menunjukkan perhatian dan kemauan untuk membantu pasien. Hal ini sesuai dengan pendapat Wijono (2008) bahwa perhatian petugas kepada pasien dapat menimbulkan rasa nyaman dan memberikan kepuasan kepada 
pasien. Hal ini membuat pasien dan keluarga merasa dihargai, diperhatikan dan mengurangi rasa cemas. Petugas yang menunjukkan perhatian terhadap keluhankeluhan yang diungkapkan pasien dapat membuat pasien merada didengar dan dihargai.

Purba (2014) dalam penelitian sebelumnya, yang telah dilakukan di Puskesmas Huta Raya menunjukkan hasil kepuasan responden dalam pelayanan kesehatan berada dalam kategori puas sebesar $97,32 \%$ dan $82,52 \%$. Sehingga dapat disimpulkan kepuasan pasien dalam pelayanan kesehatan berada dalam kategori ketanggapan (responsiveness) berada dalam kategori sangat puas.

Hasil penelitian pada tabel 5 menunjukkan bahwa kepuasan pasien dalam pelayanan kesehatan di Puskesmas Pembantu Pararapak berdasarkan dimensi jaminan (assurance) harapan berada dalam kategori sangat puas sebesar $64,4 \%$ sedangkan dalam kenyataan berada dalam kategori sangat puas sebesar $60 \%$. Responden menyatakan kepuasan dalam item petugas Puskesmas Pembantu Pararapak bersikap ramah kepada pasien. Hal ini sejalan dengan pendapat dari Atep (2003) bahwa sikap santun dan ramah disertai dengan tutur kata yang baik adalah wujud penghormatan untuk menghargai pasien. Hal ini berkontribusi besar pada kepuasan pasien dalam pelayanan kesehatan yang diberikan. Hasil penelitian ini menunjukkan bahwa kesembuhan seseorang tidak hanya bersumber dari kesembuhan fisik tetapi juga secara psikis. Dapat dikatakan bahwa Puskesmas Pembantu Pararapak dapat memberikan pelayanan dimensi jaminan (assurance) yang sangat memuaskan kepada pasien yang dilayani.

Kepuasan pelayanan pada dimensi jaminan (assurance) berada dalam kategori puas juga sejalan dengan Purba (2014) penelitian di Puskesmas Huta Rakyat menyebutkan kepuasan pelayanan pada dimensi jaminan (assurance) berada dalam kategori puas. Candrawati (2015) menemukan kepuasan pasien dalam pelayanan kesehatan pada dimensi jaminan (assurance) berada dalam kategori puas sebesar $97,32 \%$ dan $82,52 \%$.

Tabel 6 menunjukkan bahwa kepuasan pasien dalam pelayanan kesehatan di Puskesmas Pembantu Pararapak berdasarkan dimensi empati (empathy) harapan berada dalam kategori puas sebesar $57,8 \%$, sedangkan dalam kenyataan berada dalam kategori puas sebesar 44,4 \%. Responden memberikan kepuasan pada item petugas kesehatan memahami kebutuhan pasien. Peneliti berpendapat hal ini terjadi karena pasien selalu merasa nyaman dan diperhatikan saat mereka berkeluh kesah tentang penyakitnya maupun permasalahan yang berhubungan dengan kesehatan anggota keluarganya. Sejalan dengan pendapat Pohan (2007) yang menyatakan layanan kesehatan yang bermutu harus mampu menyediakan informasi yang jelas tentang apa, siapa, kapan, dimana dan bagaimana layanan kesehatan akan dan atau telah dilaksanakan. Hal ini dapat membantu pasien untuk berpartisipasi dalam mengambil keputusan medis dan menentukan keberhasilan pemulihan kesehatan pasien. Pasien yang merasa dipahami dan dilibatkan dalam pengambilan keputusan tentang pengobatannya akan merasa puas dalam pelayanan kesehatan yang diterimanya.

Pengukuran kepuasan pasein juga dilakukan dengan menjumlahkan hasil pada keseluruhan lima dimensi dengan menggunakan skor gap. Sehingga dapat dilihat nilai dari kepuasan pasien dalam pelayanan kesehatan di Puskesmas Pembantu Pararapak secara keseluruhan. Grafik 1 menggambarkan bahwa kepuasan 
pasien dalam pelayanan kesehatan di Puskesmas Pembantu Pararapak secara keseluruhan dimensi, berdasarkan harapan berada dalam kategori sangat puas sebanyak 41 responden $(91,11 \%)$ sedangkan dalam kenyataan berada dalam kategori sangat puas sebanyak 38 responden $(84,4 \%)$. Secara garis besar didapatkan hasil bahwa pasien merasa sangat puas dengan pelayanan yang diberikan petugas kesehatan. Meskipun terdapat kesenjangan antara harapan dan kenyataan dimana persentase harapan masih lebih besar, yang disebabkan adanya beberapa kriteria yang masih rendahnya nilai kepuasan dalam hal kenyataan.

Kepuasan konsumen adalah perasaan konsumen setelah membandingakn antara apa yang dia terima dengan harapannya (Husein, 2005). Jika seseorang merasa pupas dengan nilai yang diberikan oleh produk atau jasa, kemungkina besar ia akan menjadi pelanggan dalam waktu yang lama. Dalam konsep kepuasan terdapat dua elemen yang mempengaruhi, yaitu harapan dan kinerja (Yamit, 2005). Apabila kinerja tidak sesuai harapan maka hasilnya adalah kecewa. Bila kinerja sesuai dengan harapan maka hasilnya puas. Bila kinerja melebihi harapan maka akan timbul perasaan sangat puas, demikian pula sebaliknya.

Beberapa syarat yang harus dipenuhi agar pelayanan kesehatan dapat mencapai tujuan yang diinginkan. Menurut Azwar (2006) terdapat delapan hal pokok yaitu, ketersediaan pelayanan kesehatan, kesinambungan pelayanan kesehatan, penerimaan pelayanan kesehatan, kewajaran pelayanan kesehatan, ketercapaian pelayanan kesehatan, keterjangkauan pelayanan kesehatan dan mutu pelayanan kesehatan.

Puskesmas dapat melaksanakan fungsinya dengan cara antara lain merangsang masyarakat termasuk swasta untuk melaksanakan kegiatan dalam rangak menolong diri sendiri. Puskesmas dapat memberikan petunjuk kepada masyarakat tentang bagaimana menggali dan menggunakan sumber daya yang ada secara efektif dan efisien. Puskesmas juga memberikan bantuan yang bersifat bimbingan teknis materi dan rujukan medis maupun rujukan kesehatan kepada masyarakat denagn ketentuan bantuan tersebut tidak menimbulkan ketergantungan. Pelayanan kesehatan langsung kepada masyarakat dan bekerja sama dengan sektor-sektor yang bersangkutan dalam melaksanakan program puskesmas.

Peneliti berpendapat sebagai institusi pelaksana teknis, puskesmas memiliki peran yang sangat vital. Dalam konteks otonomi daerah saat ini puskesmas dituntut memiliki kemampuan manajerial dan wawasan jauh ke depan untuk meningkatkan kualitas pelayanan kesehatan. Untuk itu mempertahankan kepuasan pasien terhadap pelayanan kesehatan yang diberikan sangat penting, mengingat puskesmas adalah ujung tombak layanan kesehatan.

\section{KESIMPULAN}

Secara keseluruhan hasil penelitian dapat disimpulkan kepuasan pasien dalam pelayanan kesehatan di Puskesmas Pembantu Pararapak berada dalam kategori sangat puas. Saran yang dapat diberikan adalah Puskesmas diharapkan tetap mempertahankan bahkan meningkatkan kualitas pelayanan yang paripurna bagi pasien rawat jalan yang datang berkunjung ke Puskesmas Pembantu Pararapak. Penelitian ini dapat dilanjutkan dengan meneliti tentang budaya kearifan lokal yang mendukung kepuasan pasien berobat ke Puskesmas Pembantu Pararapak. 


\section{DAFTAR PUSTAKA}

Asmarani, Cut Nur. 2013. Evaluasi Tingkat Kepuasan Pasien terhadap Pelayanan Dasar Puskesmas Padang Panyang Kecamatan Kuala Pesisir, Kabupaten Nagam Raya. Skripsi.

http://repository.utu.ac.id/411/1/BA B\%20I V.pdf

Astuti, Davia Sri Astuti. Lutfi, Mohamad. 2019. Analisis Pengaruh Kualitas Pelayanan dan Kepuasan Pelanggan Terhadap Loyalitas Pelanggan. Jurnal Ekobis Vol 9, No 2 (2019). http://ejournal.stiemj.ac.id/index.php lekobis/article/view/64

Atep, Adya Barata. 2003. Dasar-dasar Pelayanan Prima. Jakarta. Elex Media Komputindo

Azwar. 2006. Menjaga Mutu Pelayanan Kesehatan Aplikasi Prinsip Lingkaran Pemecahan Masalah. Jakarta. Pustaka Sinar Harapan

Cahyono. 2008. Membangun Budaya Keselamatan Pasien dalam Praktik Kedokteran. Yogyakarta. Penerbit Kanisius

Candrawati, Anak Agung Ayu. 2015. Perbedaan Tingkat Kepuasan Pasien Pada Puskesmas ISO dan Puskesmas Non ISO di Kota Denpasar. Tesis S2 Program Studi Ilmu Kesehatan Masyarakat Program Pasca Sarjana, Universitas Udayana Denpasar

Hadi, Puyan Lukman. Prabowo, Tri. Yulitasari, Brune Indah. 2013. Komunikasi Terapeutik Perawat Berhubungan Dengan Tingkat Kepuasan Pasien di Puskesmas Dukun Magelang. Jurnal Ners dan Kebidanan Indonesia Vol 1, No 1 (2013) https://ejournal.almaata.ac.id/index.p hp/JNKI/article/view/230

Hafizurrachman. 2004. Pengukuran Kepuasan Suatu Institusi Kesehatan. Jakarta. EGC

Husein, Umar. 2005. Metode Penelitian Untuk Tesis dan Bisnis. Jakarta. Grafindo Persada

KBBI.2020.

https://kbbi.kemdikbud.go.id/entri/ke puasan

Nurba. 2012. Analisis Tingkat Kepuasan Pelayanan Publik pada Puskesmas Loa Janan. Jurnal EKSIS Vol 8 No 2 Hal. 2298-2308

Parasuraman, A. Zeithmal, VA and Berry, L.L. 1998. SERVQUAL: A Multiple Item Scale for Measuring Consumer Perceptions of Service Quality. Journal of Retailing, Vol 64 No 1 http://mkm.helvetia.ac.id/2018/04/06 /servqual-parasuraman/

Permenkes No 75 Tahun 2014 Tentang Pusat Kesehatan Masyarakat. https://dinkes.gunungkidulkab.go.id/ wpcontent/uploads/2014/10/PermenkesNo-75-Th-2014-ttg-Puskesmas.pdf

Pohan, Imbolo. 2007. Jaminan Mutu Layanan Kesehatan. Jakarta. Penerbit Buku Kedokteran EGC

Purba, Dame Tika O. 2014. Tingkat Kepuasan Pasien Terhadap Pelayanan Kesehatan di Puskesmas Huta Rakyat Kecamatan Sidikalang Kabupaten Dairi. Fakultas Keperawatan, Universitas Sumatra Utara. Skripsi. http://repository.usu.ac.id/bitstream/ handle/123456789/44659/Abstract.p df? sequence $=6 \&$ isAllowed $=y$ 
Satrianegara, M. Fais. 2014. Organisasi dan Manajemen Pelayanan Kesehatan. Jakarta: Salemba Medika

Tando, Naomi. 2013. Mutu Layanan Kebidanan dan Kebijakan Kesehatan. Jakarta : In Media

Utama, Widya. Lestari, Wien. dan Ikmaluhakim, Dihen Reksa. 2017. Pengukuran Kepuasan Pasien terhadap Pelayanan Puskesmas dengan Metode Servqual (Studi Kasus Puskesmas Ngagel Rejo Surabaya). Conference Paper. Seminar Nasional Multi Disiplin Ilmu Unisbank 2017. https://www.neliti.com/publications/ 174337/pengukuran-kepuasanpasien-terhadap-pelayananpuskesmas-dengan-metode-servqual$\underline{\mathrm{S}}$

Wijono. 2008. Manajemen Mutu Rumah Sakit dan Kepuasan Pasien: Prinsip dan Praktik. Surabaya. CV Duta Prima Airlangga

Yamit, Zulian. 2005. Manajemen Kualitas Produk dan Jasa Edisi 1 Cetakan 4. Yogyakarta. Ekonisia Kampus Fakultas Ekonomi UII Yogyakarta

Zeithaml, Valarie A and Bitner, MJ. 2000. Service Marketing 2nd Edition: Integrating Customer Focus. New York McGraw-Hill Inc 